\title{
Pulmonary artery rupture in pregnancy complicating patent ductus arteriosus
}

\author{
Nicholas J Green, Terence P Rollason
} Department of
Pathology, Maternity Hospital, Queen Elizabeth Medical Centre, Edgbaston, Birmingham N J Green T P Rollason

Correspondence to Dr Nicholas J Green, Department of Pathology, Birmingham Maternity Hospital, Queen Elizabeth Medical Centre, Edgbaston Birmingham B15 2TG.

Figure 1 Necropsy appearance of the heart and pulmonary artery, showing dilatation of the main pulmonary artery and right ventricular hypertrophy. The probe marks the site of pulmonary artery rupture.

\begin{abstract}
Fatal haemopericardium in a 27 year old pregnant woman was caused by rupture of a dissecting aneurysm of the pulmonary artery. She had an uncorrected patent ductus arteriosus and severe pulmonary hypertension. The wall of the pulmonary artery showed atherosclerosis and cystic medionecrosis.
\end{abstract}

(Br Heart J 1992;68:616-8)

\section{Case report}

A 27 year old West Indian woman with a patent ductus arteriosus had been clinically well and took no medication. Cardiac catheter studies when she was 13 years old had shown pulmonary hypertension with pressures of $70 /$ $40 \mathrm{~mm} \mathrm{Hg}$. There was reversal of the shunt during exercise (right-to-left), indicating that she was unsuitable for surgery and therefore the patent ductus had remained uncorrected. On examination, the apex beat was displaced laterally to the anterior axillary line and there were signs of pulmonary hypertension-loud pulmonary heart sound $\left(\mathbf{P}_{2}\right)$ and a palpable pulmonary artery. There was a long early diastolic murmur of pulmonary regurgitation and an ejection systolic murmur. An electrocardiogram showed evidence of right ventricular hypertrophy.

Her first pregnancy, when she was 25 years old, had been uneventful; however, there had been clinical signs of increasing pulmonary hypertension. At 38 weeks' gestation a normal female infant was delivered through the vagina. Immediately post partum the mother developed a pyrexia, which was thought to be endocarditis, and this settled on antibiotics. She was strongly advised to avoid further pregnancy.

The second pregnancy, two years later, was progressing well and she was admitted to hospital for bed rest. She died unexpectedly in bed at 33 weeks' gestation.

\section{Necropsy and histological findings}

The body was thin but well nourished (height $163 \mathrm{~cm}$, weight $54.6 \mathrm{~kg}$ ). There was a large haemopericardium caused by rupture of a dissecting aneurysm of the main pulmonary artery into the pericardial sac at the base of the heart. The main pulmonary trunk was dilated to $5 \mathrm{~cm}$ in diameter and the dissection originated in a raised atheromatous plaque on the anterior aspect of the pulmonary artery $3 \mathrm{~cm}$ above the pulmonary valve (figs 1 and 2 ). There was a large patent ductus arteriosus (diameter $2 \mathrm{~cm}$ ) leading to an aorta of normal calibre. The right ventricle was hypertrophied $(100 \mathrm{~g})$. The left ventricle including the septum weighed $160 \mathrm{~g}$. There was no other gross cardiac malformation.

Histological examination of the main pulmonary artery showed a striking accumulation of alcianophilic mucopolysaccharide in the media (cystic medionecrosis) (fig 3) with dissection between the inner and outer halves. There were also small amounts of medial alcianophilic mucin in the aorta. In the lungs there were widespread severe hypertensive changes with plexiform lesions (plexigenic pulmonary arteriopathy).

No other anatomical or histological abnormality of significance was seen and the fetus was normal. 
Figure 2 Necropsy appearance of the opened main pulmonary artery, showing atherosclerosis. The arterial dissection is seen in the cut edge of the pulmonary trunk (arrow).

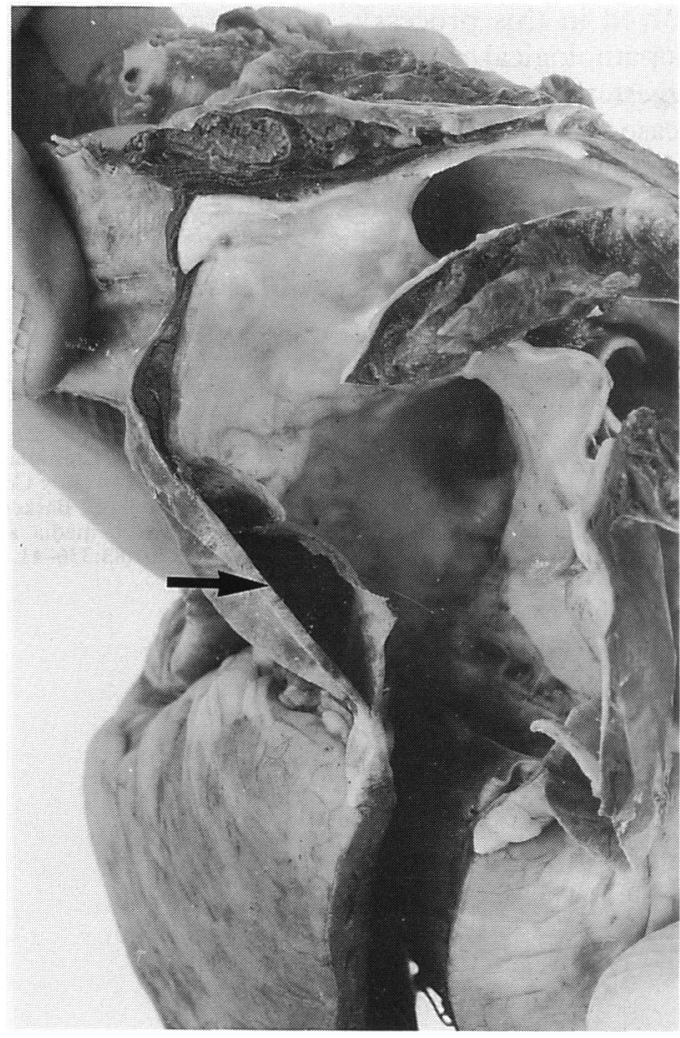

\section{Discussion}

Pulmonary artery aneurysm is a rare condition and is invariably associated with pulmonary hypertension. In a necropsy review of 111 cases, ${ }^{1}$ pulmonary hypertension due to cardiac malformation was present in $66 \%$. Patent ductus arteriosus was the commonest single lesion, occurring in combination with $22 \%$ of aneurysms.
When Coleman et $a l^{2}$ reviewed published reports they found only six cases of ruptured pulmonary artery aneurysm associated with patent, ductus arteriosus alone, in addition to their own. There have been reports of two more cases. ${ }^{34}$ We identified only one report of rupture in pregnancy, ${ }^{5}$ however, this was associated with pulmonary infundibular stenosis as well as patent ductus arteriosus. There is also a report of a maternal death occurring 17 hours post partum owing to pulmonary artery dissection associated with a patent ductus alone, ${ }^{6}$ presumably precipitated by labour. Our case is the only report we found of rupture during pregnancy associated with a patent ductus as the only anatomical abnormality.

Cystic medionecrosis is usually associated with dissection of the pulmonary artery ${ }^{3}$ as is atheroma and our case is no exception. Indeed both are known to be related to severe pulmonary hypertension.

This case emphasises the possibility of arterial dissection in pregnancy, particularly in the presence of pre-existing cardiovascular disease. This association has been well described previously, in particular by Guthrie and MacLean ${ }^{7}$ who showed that nine of 57 nonaortic arterial dissections in women occurred either during pregnancy or shortly after delivery.

It is of interest to speculate on the cause of the apparently increased incidence of both systemic and pulmonary arterial dissections in pregnancy. It has been suggested that the increase in body water in pregnancy is in part taken up by connective tissue mucopolysaccharides. ${ }^{8}$ Robertson pointed out there is no reason why mucopolysaccharides in the vessel
Figure 3 Histological section showing pools of mucopolysaccharide in the media of the pulmonary artery (haematoxylin and eosin; original magnification, $\times 500$ )

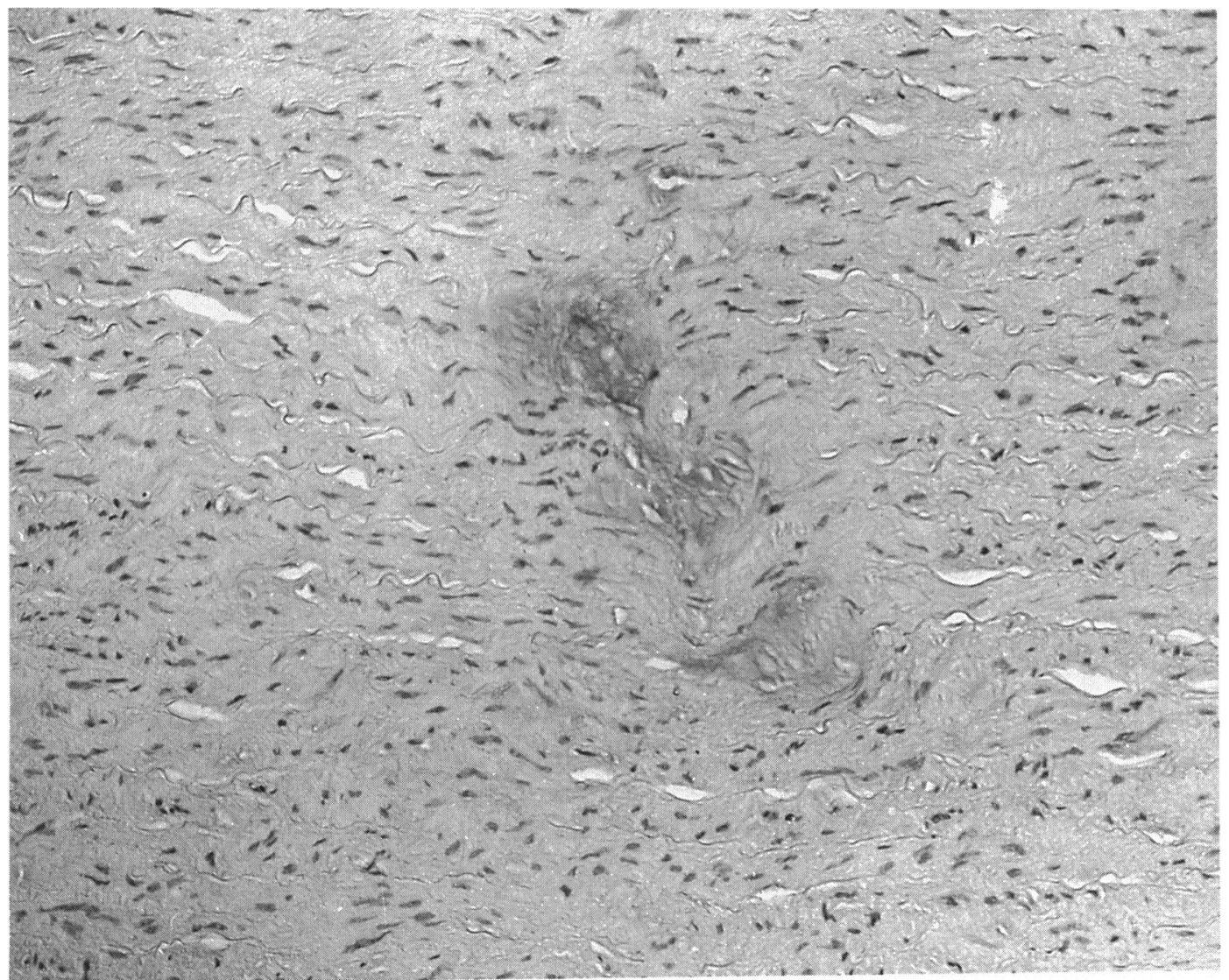


wall should not be involved in this process"; indeed there is some histopathological evidence that they are. ${ }^{10} \mathrm{We}$ suggest that the likeliest course of events in our case was cystic medionecrosis and atheroma, followed by dissection and rupture. These were consequent upon the increased cardiac output and exaggeration of mucopolysaccharide deposition associated with pregnancy.

We thank Dr R M Whittington, HM Coroner for the District of Birmingham and Solihull for permission to report this case.

1 Boyd LJ, McGavack TH. Aneurysm of the pulmonary artery. Am Heart $J$ 1939;18:562-78.

2 Coleman M, Slater D, Bell R. Rupture of pulmonary artery aneurysm associated with persistent ductus arteriosus. $\mathrm{Br}$ Heart J 1980;44:464-8.
3 Nguyen G-K, Dowling GP. Dissecting aneurysm of the pulmonary trunk. Arch Pathol Lab Med 1989;113:1178-9. Sardesai SH, Marshall RJ, Farrow R, Mourant AJ. DissectSardesai SH, Marshall RJ, Farrow R, Mourant AJ. Dissect-
ing aneurysm of the pulmonary artery in a case of ing aneurysm of the pulmonary artery in a case of
unoperated patent ductus arteriosus. Eur Heart $J 1990$; unoperated

5 D'Arbela PG, Mugerwa JW, Patel AK, Somers K Aneurysm of pulmonary artery with persistent ductus arteriosus and pulmonary infundibular stenosis. Fatal dissection and rupture in pregnancy. Br Heart $J 1970$ 32:124-6.

6 Hankins GDV, Brekken AL, Davis LM. Maternal death secondary to a dissecting aneurysm of the pulmonary artery. Obstet Gynecol 1985;65(suppl):45-8.

7 Guthrie W, MacLean H. Dissecting aneurysms of arteries other than the aorta. J Pathol 1972;108:219-35.

8 Robertson EG. Oedema in normal pregnancy. $J$ Reprod Fertil 1969;9(suppl):27-36.

9 Robertson WB. Uteroplacental vasculature. J Clin Pathol 1976;Suppl 10 (Roy Coll Path):9-17.

10 Manalo-Estrella P, Barker AE. Histopathologic findings in human aortic media associated with pregnancy. Arch Pathol 1967;83:336-41. 